\title{
Too many authors spoil the credit
}

\author{
Eldon Shaffer MD FRCPC
}

S ngle authorship was the norm eons ago. According to rabbinical tradition, Moses wrote the five books of the Jewish bible, the Torah, meaning 'Instruction' or 'Law'. Christian scholars credit God with breathing out the Bible. Before the mid-20th century, landmark scientific works from giants, such as Newton, Einstein and Fermi, were single authored. Although single authors wrote the vast majority (>98\%) of important medical articles a century ago, this has become a rarity; $<5 \%$ are now single authored. Meanwhile, the number of multiauthored articles has escalated, many of which list individuals who made insignificant contributions (1). At times, the list of authors reaches astronomical numbers, occupying as much space as the corresponding abstract. Extreme examples include a report in the physical sciences on the Large Hadron Collider listing almost 3000 authors, and a clinical trial published in The New England Journal of Medicine listing 974 authors (2). The basis for this rise in multiple authors does not simply reside in the complexities of current medical bioscience or the need for large multicentred clinical trials. Unmerited authorship is rampant. Twenty to thirty percent of medical science authors do not contribute substantially to the eventual peer-reviewed publication, particularly in large, multi-authored articles $(1,3)$. One facet of undeserved authorship increasingly occurs in the form of 'honorary authorship' (ie, named authors who do not significantly contribute), which is granted either to chairs of departments as a convention or to more senior authors to boost the paper (4). Another is 'ghost writers' (unnamed authors who do contribute), employed by some biotechnology companies, aiming to lever 'key opinion leaders' and, so, portray the publication as originating in the academic domain, unsullied by commercial interests (5).

To assess original articles appropriately, scientists and clinicians must know the proper authorship and the origin and execution of the study, devoid of ghost writing or other bias. For the academic, authorship represents the means by which peers perceive their scholarly work. This establishes their reputation, productivity, grant support and opportunity for promotion.

The order in which authors are listed quantitatively identifies credit. Although there are some differences among disciplines, most have the authors listed according to the magnitude of their involvement in the work, placing the principal investigator last. Because some journals, such as Gastroenterology, limit authorship lists in the references to contain a maximum of three followed by the near afterthought 'et al', the senior author may select the third position so as to appear in any subsequent citations. Many publications, however, allow up to six authors before 'et al' (eg, Canadian Journal of Gastroenterology and Hepatology, Hepatology) to be listed in the references. Thus, this practice has disappeared.

To accommodate the growing number of authors per article, institutions and journals have established guidelines that seek to clarify the role, involvement and responsibility of each author. Since 1985, a voluntary, closed-membership group of select general medical editors (the International Committee of Medical Journal Editors) has provided guidance on authorship that continually evolves with time. This committee of editors provides clarification on accountability, roles and responsibilities of authors, fraud, conflict of interest and clinical trial registration. The International Committee of Medical Journal Editors "recommends that authorship be based on the following 4 criteria: substantial contributions to the conception or design of the work; or the acquisition, analysis, or interpretation of data for the work; AND drafting the work or revising it critically for important intellectual content; AND final approval of the version to be published; AND agreement to be accountable for all aspects of the work in ensuring that questions related to the accuracy or integrity of any part of the work are appropriately investigated and resolved" (6). In its instructions to authors, the Canadian Journal of Gastroenterology and Hepatology fulfills some of these criteria: requesting a letter to indicate that all authors have participated in the research, and have reviewed and agree with the contents of the article. Few articles, however, clarify the actual contributions of the authors.

Authorship assigns responsibility and attributes credit. Substantive contribution must be a primary criterion. This should include significant involvement in the three components of any scientific publication: its original conception and design; implementation of the study including data collection and analysis; and, finally, writing major sections of the manuscript while being accountable for all of its content. Such decisions about authorship and order in the publication is best identified by the research team engaging in an open conversation. This should begin with the design of the study and continue throughout its implementation and manuscript submission. Recognizing individuals whose role represents a limited contribution may best be communicated through an 'Acknowledgement' section.

Multiple authors are necessary in this increasingly complex biomedical world. Even in biblical times, 40 different authors from three continents, writing in three different languages, created the Bible. Moses required help to complete Deuteronomy as the last portion covered a time after his death.

\section{REFERENCES}

1. Shapiro DW, Wenger NS, Shapiro MF. The contributions of authors to multiauthored biomedical research papers. JAMA 1994:271:438-42.

2. Osborne JW, Holland A. What is authorship, and what should it be? A survey of prominent guidelines for determining authorship in scientific publications. Practical Assessment Research and Evaluation 2009;14:No.14.

3. Wislar JS, Flanagin A, Fontanarosa PB, DeAngelis CD. Honorary and ghost authorship in high impact biomedical journals: A cross sectional survey. BMJ 2011;343:d6128.

4. Drenth JP. Multiple authorship: The contribution of senior authors. JAMA 1998;280:219-21.

5. Matheson A. How industry uses the ICMJE Guidelines to manipulate authorship - and how they should be revised. PLoS Med 2011;8:e1001072.

6. International Committee of Medical Journal Authors (ICMJE). Defining the role of authors and contributors 2014. <www.icmje.org/ recommendations/browse/roles-and-responsibilities/defining-the-roleof-authors-and-contributors.html> (Accessed October 17, 2014).

Division of Gastroenterology and Hepatology, University of Calgary, Calgary, Alberta

Correspondence: Dr Eldon Shaffer, Division of Gastroenterology and Hepatology, University of Calgary, Room 6D48, 3280 Hospital Drive

Northwest, Calgary, Alberta T2N 4N1. Telephone 403-220-8457, fax 403-592-5090, e-mail shaffer@ucalgary.ca

Received and accepted for publication October 20, 2014 


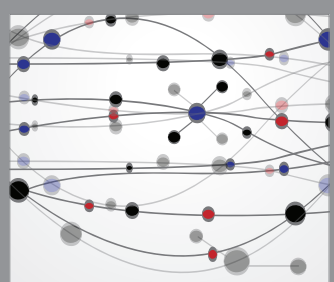

The Scientific World Journal
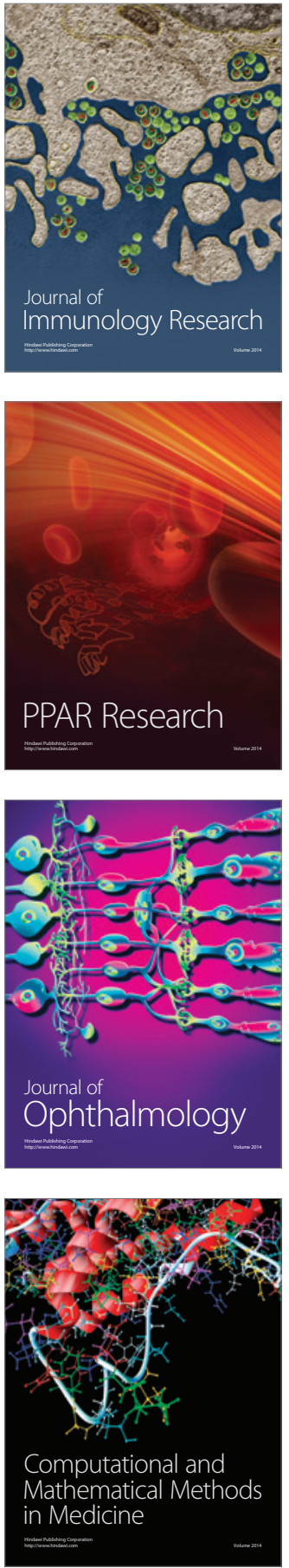

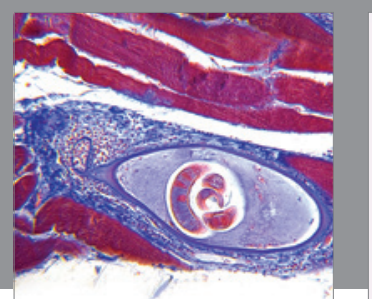

Gastroenterology Research and Practice

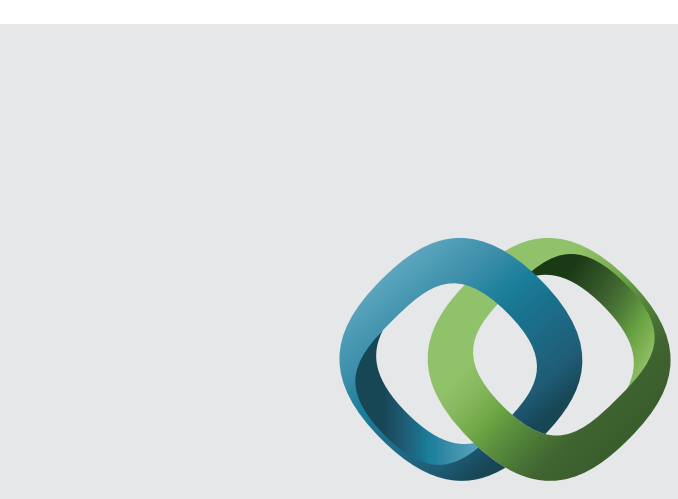

\section{Hindawi}

Submit your manuscripts at

http://www.hindawi.com
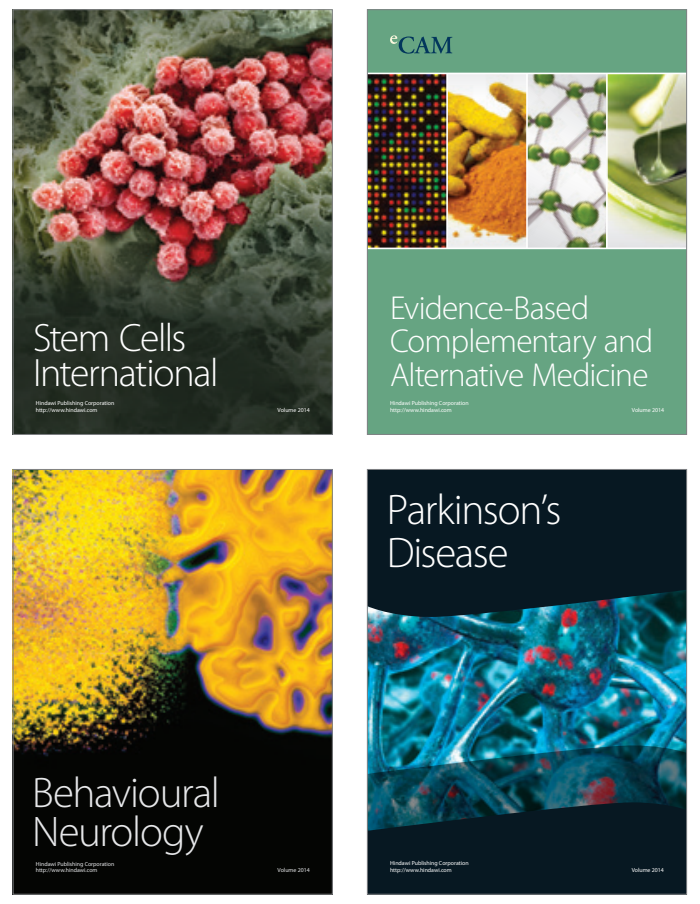
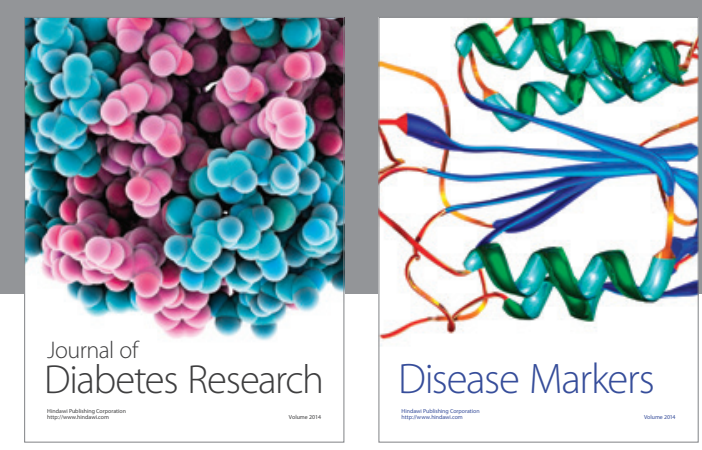

Disease Markers
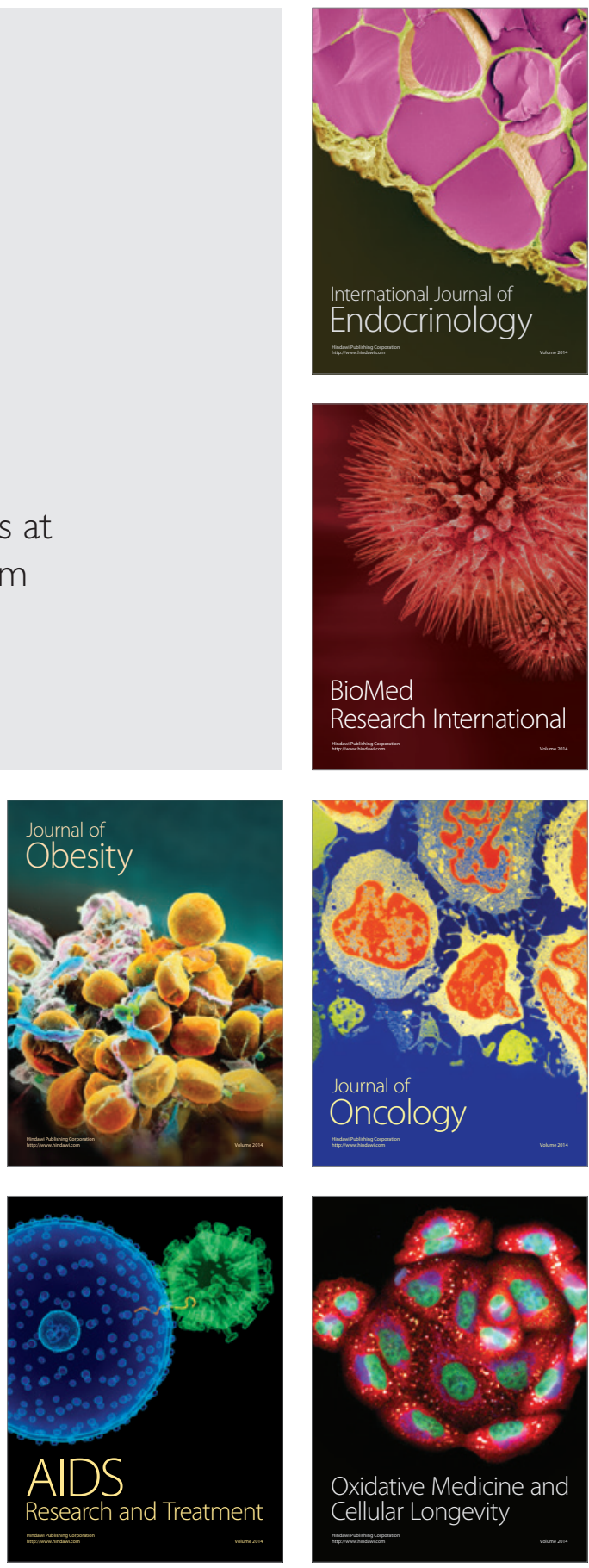